\title{
The Liaison Interpreter's Role as an Intercultural Mediator: A Cognitive-Pragmatic Approach
}

\author{
Shuangjiao Wu \\ College of English, Zhejiang Yuexiu University, Shaoxing, China \\ Email: sky_shuangjiao@163.com
}

How to cite this paper: Wu, S. J. (2021). The Liaison Interpreter's Role as an Intercultural Mediator: A Cognitive-Pragmatic Approach. Open Journal of Modern Linguistics, 11, 90-103.

https://doi.org/10.4236/ojml.2021.111008

Received: January 7, 2021

Accepted: February 17, 2021

Published: February 20, 2021

Copyright $\odot 2021$ by author(s) and Scientific Research Publishing Inc. This work is licensed under the Creative Commons Attribution International License (CC BY 4.0).

http://creativecommons.org/licenses/by/4.0/

\begin{abstract}
Liaison interpreting is a type of interpreting performed in cross-cultural communications. The role of liaison interpreters has been studied by scholars for many years. For a long time, interpreting has been regarded as a communication activity, which solely converted languages and transferred the linguistic meaning of the original utterances. However, the practitioners and researchers began to realize that interpreting is a bilingual as well as bicultural communication activity. It bridges the cultural gap for people who don't share the same language or cultural background. Therefore, this paper proposes an account of the liaison interpreter's role as intercultural mediator as an alternative to other accounts of the interpreter's role in the literature on liaison interpreting. The account of the liaison interpreters' role as intercultural mediator is derived from the principles of a theoretical framework that draws on the findings of the theory of sense (Seleskovitch and Lederer, 1995) and Sperber and Wilson's $(1986,1995)$ relevance theory of communication (RT). The account provides the basis for formulating a clearer definition of the concept of intercultural mediation in the context of liaison interpreting (LI). With data from authentic examples from interpreters' actual performance, this paper intends to analyze interpreter's role as an intercultural mediator in interactions within the framework of cognitive-pragmatic approach (CPA). In order to enhance liaison interpreters' competence of cultural mediation, the paper then provides some implications for interpreters training in China.
\end{abstract}

\section{Keywords}

Liaison Interpreting, Liaison Interpreter, Cultural Mediation, Cultural Mediator, Cognitive-Pragmatic Approach (CPA) 


\section{Introduction}

Liaison interpreting is frequently used in cross-cultural communications. The role of liaison interpreters has been researched by scholars for many years. For a long time, interpreting, including liaison interpreting, has been regarded as a communication activity, which solely converted languages and transferred the literal meaning of the original utterances. However, the practitioners and researchers have begun to realize that interpreting is a bilingual as well as bicultural communication activity. It bridges the cultural gap for people who come from different cultural backgrounds. In other words, interpreting is an act of communication which attempts to relay another act of communication across cultural and linguistic boundaries. Liaison interpreting by nature is an act of cross-cultural communication.

Within the last decades, researchers such as Harriers (1995), Wadensjö (1998), Roy (2000) and Angelelli $(2000,2004)$ in the West have begun to conduct researches on liaison interpreting. And studies on liaison interpreting in China have been prospering over the past few years.

\subsection{Study of Liaison Interpreting in the West}

During the period from 1940s to 1960s, much attention of practitioners and researchers has been paid to conference interpreting. However, the academic attention from 1970s and 1980s has been directed towards community interpreting or liaison interpreting.

The two hundred and fifty people who gathered at Geneva Park from June 1 to June 4 in 1995 were attending a historic event in the evolution of professional interpreting-The Critical Link: Interpreting in Legal, Health, and Social Service Settings (Harriers, 1995: p. 1). Since then, the international conferences on community interpreting have been held around the world-Critical Link 2: Standards and Ethics in Community Interpreting: Recent Development was held in Canada in 1998; The Critical Link 3: The Complexity of the Profession in Canada 2001; The Critical Link 4: Professionalism of Interpreting in the Community in Sweden in 2004 and The Critical Link 5: Quality in Interpreting: A Shared Responsibility in Australia in 2007. The international conferences on community interpreting have facilitated the professionalism of liaison interpreting and the intercommunication among researchers (Ren, 2010: 25)1.

According to Interpreting as Interaction (1998) by Cecilia Wadensjö, community interpreting is a communication process with three participants including the interpreter. It by nature is bilingual as well as bicultural. Cynthia Roy proposed in Interpreting as a Discourse Process (2000) that a qualified interpreter is a discourse analyzer by looking into the role of sign language interpreter in mediating the turn exchanges. In Medical Interpreting and Cross-cultural Communication (2000) and Revisiting the Interpreter's Role (2004) by Claudia Angelelli proved the visibility of medical interpreter.

${ }^{1}$ It is translated by the author, and the author should take the responsibility for the translation. 
The researches on liaison interpreting mentioned above point out that a liaison interpreter is visible and takes on the role as a participant during the interaction encounters. Even though academic attention has been shifted to liaison interpreter's involvement in cross-cultural communications, the liaison interpreter's role as an intercultural mediator hasn't been fully discussed.

\subsection{Study of Liaison Interpreting in China}

The number of studies in the field of interpreting has substantially increased in the past few years. But the researches are still limited when compared with those in the area of translation. Among the limited researches in interpreting, much attention has been brought to conference interpreting. However, the attention has been directed towards liaison interpreting from conference interpreting. Therefore, researches on liaison interpreting have shown a positive trend over the past few years.

Topics on liaison interpreting mainly explored by researchers over areas such as teaching methods and skills training suggestions, cultural differences and dealing strategies in liaison interpreting. The dealing strategies often proceed from the perspective of raising the interpreter's intercultural awareness or discussing role orientation of liaison interpreters.

The researches on teaching methods and training skills of liaison interpreting are confined to the level of interpreters' skills training, which don't involve the cultural elements in liaison interpreting. While the studies on cultural differences and dealing strategies are somewhat general. Subjectivity consciousness of liaison interpreters has been discussed by Ren Wen (2010) in The Liaison Interpreter's Subjectivity Consciousness, and Xu (2019) in The Construction of Subjectivity of Football Liaison Interpreters. However, the study by Ren is carried out from the perspective of liaison interpreter's visibility and empowerment consciousness, and the interpreter's non-neutrality stance. While the study by $\mathrm{Xu}$ is carried out from the perspective that how subjectivity of football liaison interpreters is constructed. The research thus is not enough from the perspective of a liaison interpreter's role as an intercultural mediator.

Therefore, this paper proposes an account of the liaison interpreter's role as intercultural mediator as an alternative to other accounts of the interpreter's role in the literature on liaison interpreting.

The account of the liaison interpreters' role as intercultural mediator is derived from the principles of a theoretical framework that draws on the findings of the theory of sense (Seleskovitch and Lederer, 1995) and Sperber and Wilson's $(1986,1995)$ relevance theory of communication (RT).

\section{Theoretical Framework}

The theoretical framework draws on two cognitive models: the theory of sense (Seleskovitch and Lederer, 1995) and relevance theory of communication (RT) developed by Sperber and Wilson $(1986,1995)$. 
The theory of sense was developed by the founder of the Paris School, Seleskovitch, in the late 1960s. Proponents of the theory of sense have been forerunners in contending that language comprehension is a dynamic process that occurs/can be established whenever units of linguistic meaning are merged with prior (extralinguistic) knowledge (Seleskovitch and Lederer, 1995: p. 23) to "make sense". The theory of sense refers to this type of extralinguistic/world knowledge as "cognitive complements" (Seleskovitch, 1978: p. 334; Lederer, 1990: p. 53), that is, "the knowledge of things that changes language meanings into author's [or speaker's] meaning or sense" (Seleskovitch, 1988: p. 87). Sperber and Wilson (1995) argue that human "cognitive processes [...] are geared to achieving the greatest possible cognitive effect for the smallest possible processing effort".

The two theories discussed above form the theoretical framework adopted in this paper (henceforth the cognitive-pragmatic approach, CPA).The model can be described as a cognitive-pragmatic one. It is cognitive because it deals with cognitive (or non-verbal) sense and pragmatic because it deals with what speakers intend to say (Al-Zahran, 2007).

The whole model can be summarised by the notion of interpretive resemblance which, theoretically, reflects the translating process since presumably interpreters aim in translating at a rendition that does not necessarily resemble the original in linguistic form, surface structure or semantic meaning, but one that interpretively resembles the original (Al-Zahran, 2007).

Thus, the Liaison interpreter (LIr) listens to and receives the speaker's output (S. OUTPUT) which is the product of the speaker's cognitive environment (SCE) that comprises an individual's perception of the world and knowledge/assumptions he/she can entertain including, but not limited to, knowledge/assumptions about culture(s) and the receiver's cognitive environment (RCE), (extra-) linguistic knowledge, experiences, memories, inferences, situation, (immediate) context, etc. (Sperber and Wilson, 1995: 38f/46; 4.2.2.2 Context).

The LIr then processes the S. OUTPUT using any relevant cognitive complements from his/her cognitive environment (ICE) while taking notes. Determining which information to use and context to select is governed by his/her search for optimal relevance, which will help him/her identify the speaker's intended meaning through inference. This process results in a non-verbal sense that interpretively resembles the original. The sense is stored partly in the LIr's memory and partly in his/her notes depending on the LIr's decisions in this regard (Al-Zahran, 2007).

The CPA as described above allows for developing an account of the LIr's role as intercultural mediator. The CPA suggests that the LIr as intercultural mediator is unlikely to impose his/her own ideas, ideological belief or opinion, cultural perceptions, projections or otherwise to what he/she interprets simply because he/she does not initiate speeches (Al-Zahran, 2007) but is rather more likely to try to represent what he/she hears as faithfully as possible by aiming for interpretive resemblance, which is governed by the principle of relevance, implies the 
process of deverbalisation offered by the theory of sense, and offers a guarantee of faithfulness to the original. Besides, since interpreters deal with languages and cultures, LIrs cannot but perform intercultural mediation to bridge the cultural gap and thus establish understanding and communication among participants of different cultures, the diversity of which could put obstacles in the way of understanding.

\section{Cultural Differences in Liaison Interpreting}

\subsection{Different Value Systems and Thinking Models}

Value systems are gradually established as people acquire communicative competence during the process of socialization. It's a part of social culture. The unique value system could guide its own people to evaluate things. In fact, it forms moral criterion, behavioral principle and living philosophy. The differences in value orientation are the roots of most cross-cultural barriers. People from different cultures behave differently according to their own value systems, which could influence the way people communicate with others. Apparently, people from eastern and western countries are embedded with different value systems.

Chinese people worship collectivism, while English-speaking people worship individualism. They believe that each individual is totally independent, and must struggle hard to meet his needs, while there is a huge number of words of kinship in Chinese. The whole society, is viewed as a big family consisted of small ones since the ancient times. A persuasive example is the ceremonial speech made in China: 尊敬的各位领导, 各位来宾, 女士们，先生们，大家好 (respected leaders, dear guests, ladies and gentlemen). While people from English-speaking countries often begin with "Mr. Chairman, Mr. Minister, etc.". A person is regarded as selfish in China, if he or she always highlights individualism. On the contrary, the English-speaking people highly value the individual contributions.

Worshiping individualism makes individuals in western countries greatly value their own privacy. It properly explains why the native speakers from the English-speaking countries feel quite absurd or offensive when they are asked about their salary or marital status and other problems concerning their privacy. Due to collectivism-centered value system, people in China often ask these questions in daily conversations, but without any offense of others' privacy.

\subsection{Different Historical Backgrounds and Cultural Images}

Culture is closely related with historical backgrounds, which are peculiar to each nation. China, with a vast territory and a large population, boasts a long history over five thousand years. In Chinese culture, even numbers represent good luck. “四平八稳” (act in a well-balanced way) and “四通八达” (extend in all directions) are used to describe good interpersonal relationship and excellent transport systems respectively. In addition, the number of "six" represents "good luck in everything" in Chinese culture. The number of "eight" sounds like the Chi- 
nese character of "fa", which means making a fortune in Chinese culture. On the contrary, people in English-speaking countries view the odd numbers as auspicious ones.

Colors are loaded with different meanings within different cultures. The phrase “红白喜事” (at weddings and funerals) is used to mean weddings and funerals in Chinese culture. If we translate the term literally as "wearing red and white", people from the western cultures will feel confused for his or her lack of knowledge of the allusion. For the symbolic meaning of red implies danger, rather than happiness or celebration in their cultures.

Cultural images are regarded as cultural symbols, which are the results of wisdom and culture formed in the long history of different nations. They are culturally unique and meaningful.

A good number of Chinese and English cultural allusions or images can properly illustrate the point. There are examples such as "Rome was not built within a day (冰冻三尺非一日之寒也)”, and “Where there is life, there is hope (留着青 山在, 不怕没柴烧), as thin as a shadow (瘦得像猴子), Talk of the devil, and he is sure to appear (说曹操, 曹操就到) etc...”. “济公” is a famous person in China, who is loved and respected Chinese people. The Chinese saying “济公劫 富救贫, 深受穷苦人民爱戴” can hardly be understood by westerners because they are not familiar with the character. However, if we interpret it as "Jigong, Robin Hood in China, took from the rich and gave the poor" through the use of analogy, the western hearer may make sense of it (Liu, 2001).

Historical background has exerted great influence on culture. Every nation has its own history which is often displayed in its culture. Names for places and names are loaded with peculiar cultural and historical connotations. Therefore, different images or phrases would be applied by people from different cultures to express particular implied meaning.

Societies of people within the same country might share diverse beliefs and ways of expressing themselves that fall outside basic assumptions about people in the region. Therefore, liaison interpreting is an activity involving factors like source language, source culture, target language and target culture. It's crystal that cultural mediation is a prominent problem due to the cultural differences in liaison interpreting.

\section{Liaison Interpreter's Role as an Intercultural Mediator}

Therefore, in order to facilitate the communication between the primary parities, an interpreter needs to make a strategic decision on how to deal with it by deciding on an appropriate procedure to achieve the goal, that is a procedure to be dealt with through what might be termed cultural mediation procedures (AlZahran, 2007). Consider the following examples:

\subsection{Inform the Working Norms in a Particular Setting in Advance}

The participants in the interactions differ not only in the language they speak, 
but also in the cultural and social background in which the languages are embedded. When referring to cultural differences, an interpreter is facing the issues including what the cultural differences are and how the differences are individually represented. In other words, although the socio-cultural norms remain stable and upheld by all the members, the particular ways to carry the norms differ vastly. Therefore, in order to avoid possible embarrassment, an interpreter should be alert to such differences and deal with appropriately by informing the cultural differences in advance.

For instance, a topic may be appropriate in one culture, but it's inappropriate in another one. An interpreter shall inform the primary parties about the differences to avoid possible misunderstanding.

\section{Example 1:}

An interpreter shared one of her experience: Ralph \& Steven were both giving lectures in an English training center in China. They were invited to visit their supervisor on a weekend. And an interpreter was also present, because the supervisor's family members cannot speak English very well. During the dinner, the family of three including a child and the host $(\mathrm{H})$ were chatting with Ralph \& Steven. The host then had a brain twister for all the people, “究竟发生了什么事 情? ” (What do you think had happened?) All of them couldn't figure out the answer, but Ralph wanted to have a try.

$\mathrm{H}$ : 究竟发生了什么事?

I: What do you think had happened?

R: They had sex!

I: (laugh, addressing Ralph) This might be a bit inappropriate, Ralph, because usually we don't talk about sex on such occasions. Do you want to translate that?

R: (A bit embarrassed) Oh, I'm sorry. No, please don't.

I: 他说他猜不出来 (He has no idea.) (Ren, 2010:153).

Generally, a topic might be common in a culture, but it would be an impropriate, or even offensive one in another culture. When such a situation happens, the interpreter culturally mediated between speaker and audience by informing the speaker about the possible results. The interpreter in this instance determines which information to use under the governance of search for optimal relevance, which helps her identify the speaker's intended meaning through inference.

The interpreter realized that the original utterance contains cultural information that needs to be deleted partly or completely in the final rendition for effective understanding. In western countries, sex is a topic that would be discussed in public. So Ralph didn't realize his answer was inappropriate within the Chinese socio-cultural rules, especially in the current situation when a child was present. But the interpreter was aware that it could possible bring about embarrassment if she translated the words without any mediation. Then the interpreter explained the cultural differences and possible results in advance, and inquired the speaker whether to translate or not. 


\subsection{Bridge the Gap in Thinking Models between Two Cultures}

Thinking models in a particular cultural substantially influence the way people behave and communicate. What is of significance to an interpreter here is not only the awareness of such cultural differences, but also the fact that such differences are made and received differently.

Example 2:

An interpreter was hired to perform liaison interpreting for a Chinese officer and two experts from the United States-Mr. Michael and Susan. When they went back to the hotel where the experts stayed, they invited them to have a cup of coffee in the hotel, and Michael (M) said to the Interpreter (I) and the Chinese officer (C)

M: Well, thank you so much for showing us around. We had a great time today! And if you don't have other commitments, Susan and I would like to buy you two a coffee or something over there. (Pointing to the coffee bar at the corner)

I: 非常感谢您带我们去观光, 我们今天过得非常愉快。如果你们现在没有 什么别的事儿, 我跟苏珊想请你们二位到那边去喝杯咖啡。

C: 䒝呀, 不用客气, 这个是应该的嘛。这个, 算了吧。二位年纪也大了, 今天又走了一天, 肯定也很累了, 就不用麻烦了。

I: The pleasure was all ours. It was a long day. Uh, we must all a bit tired. So please don't bother. But thank you very much for your kindness. (Ren, 2010: 157-158)

It's clear from the above that all the highlighted part in the Chinese original is missing from the interpreter's version. The missing information reads as follows:

[...] you both are very old [...]

Instances of omission in interpreting can occur due to different reasons. They might occur due to a processing overload, thus the interpreter is forced to omit some information or because of a long-term memory or short-term memory failure. Omission might also be used by the interpreter as a cultural mediation procedure when realizing, for example, that the interpretation of some cultural information would do more harm than good if it was interpreted into the TL language by obscuring the meaning rather than making it clearer or easier to understand by the TL audience.

However, omission of vital information is not tolerated by either the CPA or any other theoretical framework because not only there is no cultural transfer (Al-Zahran, 2007), but also there is zero-resemblance or no communicated information at all, which in some cases could prove detrimental to the communication process (Al-Zahran, 2007). According to Chinese culture, there are strict rules to regulate the structure of the whole society. Respecting the old is regarded as a virtue in China since ancient times. Politeness in terms of address may be contained when speaking to the elder. For example, the term “您老” (the elderly)in China is showing respect to the senior people. However, being treated as the elder is a shame for the westerners. It makes them feel inferior to others. 
Therefore, people in western countries regard their age as privacy. It can therefore be argued that omission of the information is used strategically as a procedure of cultural mediation by the interpreter.

\subsection{Function as an Emotional Mediator}

When situation is impossible for an interpreter to conduct adjustment to the offensive utterances, the interpreter may omit a segment or the whole of the original utterances. When conflicts happen, the original utterances made by one primary party may be offensive. The interpreter would be asked to convey what he or she said originally. Generally, an interpreter would not follow the requirements, because it would only make the situation even worse. None of the participants can benefit from the result. And the interpreter would be the person who should be responsible for he or she is the person who "says" the abusive words directly.

The purpose that a speaker says something abusive is to inform the other party about his anger. However, ways to express anger are various, such as tone, speed, volume, facial expressions, body languages and etc. It's unnecessary to express one's anger with abusive words, which will do nothing good to the purpose of interactions. Under such circumstances, a skilled interpreter would replace the abusive expressions with other terms.

Example 3:

Here is a business case which could exemplify the point. The foreign delegate made an unreasonable requirement in a business negotiation. And a representative from the Chinese delegate was irritated that he chided. “XXX, 这老外发昏 了, 想吃天我鸟啊! (Bloody hell! The foreign delegate must go insane. It's like a toad lusting after a swan's flesh.)" The interpreter was asked to translate that. At that time, the interpreter said, "This is really too much. If you insist, I'm afraid that we can't go on." (Feng: 108) (Quoted by Ren: 2010)

As for the highlighted text in the Chinese original, the use of "a toad lusting after a swan's flesh" implies a reference to a notorious image that is strongly looked down upon. If the interpreter opted for "a toad lusting after a swan's flesh", he/she would run the risk of cause a complete failure of negotiation or even conflicts. However, the rendition in the above instance expressed the Chinese delegate's intention that they will never agree the requirement without compromising to the sense of the original and for no purpose other than establishing more effective communication with the TL audience.

Example 4:

An interpreter was escorting a foreign CEO from one of the World Top 100 companies. He was visiting a Thousand-Buddha Cave located in Xinjiang Uyghur autonomous region. The president $(\mathrm{P})$ is an archaeology enthusiast, who knows well about frescos and oil paintings. At that time, they were accompanied by two archaeologists, a local official $(\mathrm{O})$ and Mr. Xiang (X), who is a painting lover. In the fresco cavern, there were several watercolors copied by Mr. Xiang. In order to show his warm welcome, he would like to give them to the president 
as gifts.

$\mathrm{X}$ : 你跟她说, 这些画他要是喜欢的话, 我就送给他。

$\mathrm{O}$ : 这可是小向花了好几个月时间画的, 平时别人跟他要他一般不给的。

I: Mr. Xiang would like to give the paintings to you as gifts if you like them. He had spent months painting them and normally he doesn't give them up even if asked for.

P: Don't bother. (walks away)

I: (微笑, 轻声地)不用了, 不过非常感谢你的好意。(Ren, 2010: 167)

The interpreter realized that the additional information, that is he highlighted text in the above sentence, is necessary or contribute to better understanding and communication between the speaker and the TL audience. It's known to all that the Chinese people are hospitable, and they often give their favorite collections to the guests. During the above case, Mr. Xiang was polite, but he didn't know that the president was not interested at the copied works made by amateurs. However, the interpreter was impressed by Xiang's sincerity, so she added some information and some body language to make the refusal sound politer.

Thus, the additional information in this example can only contribute to more accessibility and better understanding, because it is highly unlikely the additional cultural information would trigger any reactions that are not compatible with what the speaker intends to say.

Due to the lingual and cultural differences the different power or status shared by the primary parties, people from different cultures behave vastly. A topic may probably remain within the boundary of socio-cultural rules in one culture, but sounds offensive in another culture. Due to the primary parties are unfamiliar with each other and their unique cultural norms, some behavior thus may be viewed as a face-threatening act, Different value systems and thinking models exert different impact on people from different cultures. Culture is embedded with peculiar socio-cultural rules, and people thus behave differently. In order not to make the participants feel embarrassing, an interpreter would take different dealing strategies to filter the face-threatening information.

\subsection{Criteria for Cultural Mediation}

Cultural mediation affects interactions through measures discussed above. However, the results are not always positive. As a coin has two sides, the interpreter's participation in the interpreter-mediate encounter may bring about various results. If the participation is moderate and appropriate, the interaction will be facilitated. If the involvement is excessive and improper, the result would do nothing good. Even worse, the inappropriate participation of the interpreter would irritate the primary parties and finally cause a break down or failure to the cross-cultural interactions.

In terms of the degree of participation an interpreter should excise in the interpreting, it is a delicate and complicated issue. Given on this situation, there are no set of criteria for an interpreter to consult. In real-life situation, different activity-types with different goal structures, as well as different concerns, needs, 
desires and commitments of primary parties imply different demands on the interpreter. However, there are some factors we should take into consideration.

First, settings are very important to interpreting events. Settings in which interpreting can be carried out are various. It includes formal occasions like business negotiation and informal ones like casual talking. The degree of participation is decreasing as the setting is becoming much more formal. To be specific, the more formal settings will be held in much more formal ways by the primary parties. If the interpreter's participation is not appropriate, then damage will be caused to the primary parties. Sometimes the damage caused cannot be retrieved.

When the setting of interpreter-mediated encounter is much casual, the activity will be carried out in a less formal manner. Under such circumstances, an interpreter could enjoy more freedom and be allowed to exercise more participation. However, it's worth mentioning that the situation of diplomacy interpreting is delicate. An interpreter in the diplomatic interpreting event is not permitted to exercise participation. The interpreter is always supposed to follow the original utterances of the leaders as close as possible during their discussion.

Second, the liaison interpreter's competence is another element should be taken into account. The behavior of an interpreter is determined by his or her knowledge about subject matters, cognitive competence, training and working experience. To be a qualified interpreter, one is supposed to know the knowledge of areas covering grammar, language use, organization, participant relationship and socio-cultural knowledge. An interpreter must be capable to decide on solutions very quickly. An interpreter lack of working experience is expected to remain passive and take no actions before he or she is capable enough, because it's beneficial for his or her career development. While a skilled or qualified interpreter can decide within seconds, and draw a line between his or her participation and the task of conveying meanings.

Third, an interpreter's ability of strategic competence is indispensable for a successful interaction, which could enable the interpreter to be more capable in conflict solution. Liaison interpreting has proposed much more challenges to interpreters for its peculiar characteristics. Therefore, an interpreter must acquire a better strategic competence to draw a line when his or her role as a language converter excels that as an intercultural mediator. An interpreter shoulders the responsibility of relaying and coordinating, which could exert his or her influence on the result of interaction. The interpreters in liaison interpreting shall strive for a balance between cultural mediation and literal interpreting.

\section{Implications for Interpreters Training in China}

As cultural mediation is of greater significance to liaison interpreting than other types of interpreting, a liaison interpreter's sensitivity to cultural differences is crucial to the interactions, and the development of liaison interpreter's awareness of cross-cultural communication is of greater significance. In the interpreting events, if an interpreter detects or foresees there would be considerable loss or misunderstanding if the interpreting is made literally. The interpreter should 
communicate with the speaker, by telling him the potential result of his utterance and discuss with him whether and how this utterance should be interpreted. (Like in Example 3 and Example 4)

The highest level of unconscious competence advanced by W. C. Howell who demonstrated in 1982 can be reached by four phases in the awareness development.

Stage 1: unconscious incompetence. In this stage, trainees have neither realized the cultural differences nor had the guidance on the awareness of crosscultural communication.

Stage 2: conscious incompetence. Trainees have noticed that the rendition of cultural elements deserves their attention, but still don't know the specific differences or how and when to pay attention to them.

Stage 3: conscious competence. Trainees have acquired the awareness of crosscultural communication and can consciously conduct truthful rendition.

Stage 4: unconscious competence. Trainees have gained a high level of crosscultural awareness and are quite sensitive to the cultural elements in interpreting, always having the words at hand. In this stage, having almost overcome the cultural barriers, trainees are able to react to the cultural elements habitually.

Such awareness could be only developed through various interpreting practices. An interpreter shall raise his or her intercultural awareness and during cross-cultural communication. Before the interpreting starts, he or she shall prepare for cultural mediation. During the interpreting, what the interpreter should do is not only conveying the information, but also creating an enabling environment for communication, as well as mediating or coordinating the cultural differences in language or non-language terms. In a word, an interpreter shall improve his or her language skills, raise intercultural awareness, acquire cultural knowledge and establish a correct concept. To raise the liaison interpreter's cultural competence is not an easy task. However, constant exposure to both cultures and arduous practice can slowly but surely raise the interpreter's cultural awareness.

\section{Conclusion}

With the development of globalization, international contacts have seen a substantial increase. However, the interaction among different language speakers may be hindered by linguistic and cultural barriers. Therefore, it necessitates the involvement of an interpreter during the intercultural communications. This thesis studies liaison interpreter's role as an intercultural mediator in liaison interpreting within the framework of CPA and illustrates the missions through which the interpreter's role is performed. It then provides some implications for interpreters training in China. From the study and discussion above, the following conclusions can be drawn.

1) Liaison interpreting is an intercultural activity. It goes far beyond sole transfer of linguistic messages from a source language to a target language. It actually involves in the transmission of cultural messages. For a really successful interac- 
tion, the processing of cultural barriers in liaison interpreting becomes even more critical, due to the peculiar characteristics of liaison interpreting. In this light, cultural mediation becomes extremely important to interpreters in liaison interpreting.

2) Illustrations of cultural conflicts and significance of cultural mediation in liaison interpreting show that different people from different nations behave differently. To be a qualified liaison interpreter, he or she is expected to fully conduct his or her role as an intercultural mediator.

3) In order to smooth the progression of interactions, a qualified interpreter should enhance his or her competence of intercultural mediation. It arouses our reflections on the training of interpreting talents, and the focus of traditional training shall be shifted to enhance an interpreter's cultural competence.

Furthermore, it's should be pointed out that this thesis is only a tentative study on liaison interpreter's role as an intercultural mediator within the framework of CPA. More studies on the role should be done from other perspectives.

\section{Acknowledgements}

This paper was supported by a grant of a Bidding Project of College of English, Zhejiang Yuexiu University (Research on the Training Mode of Integrated Translation Talents in the Era of Artificial Intelligence, No. KT2020136) and a grant from the Project of Blended Teaching Reform of Zhejiang Yuexiu University (Application of Blended Teaching in Consecutive Interpreting with the Use of MobiMOOC, No. JGH1901).

\section{Conflicts of Interest}

The author declares no conflicts of interest regarding the publication of this paper.

\section{References}

Al-Zahran, A. (2007). The Consecutive Conference Interpreter as Intercultural Mediator: A Cognitive-Pragmatic Approach to the Interpreter's Role. Ph.D. Thesis, Salford: University of Salford.

Angelelli, C. V. (2000). Revisiting the Interpreter's Role. Amsterdam/Philadelphia: John Benjamin's Publishing.

Angelelli, C. V. (2004). Medical Interpreting and Cross-Cultural Communication. Cambridge: Cambridge University Press. https://doi.org/10.1017/CBO9780511486616

Harriers, B. (1995). The Critical Link: Interpreters in a Community. Amsterdam/Philadelphia: John Benjamins Publishing Company.

Lederer, M. (1990). The Role of Cognitive Complements in Interpreting. In D. Bowen, \& M. Bowen (Eds.), Interpreting: Yesterday, Today, and Tomorrow (pp. 53-60). Amsterdam: John Benjamins Publishing Company. https://doi.org/10.1075/ata.iv.11led

Liu, H. P. (2001). Techniques of Interpreting. Beijing: China Translation Corporation.

Roy, C. B. (2000). Interpreting as a Discourse Process. New York: Oxford University Press.

Seleskovitch, D. (1978). Language and Cognition. In D. Gerver, \& H. W. Sinaiko (Eds.), 
Language Interpretation and Communication (pp. 333-341). Boston, MA: Springer. https://doi.org/10.1007/978-1-4615-9077-4 29

Seleskovitch, D., \& Lederer, M. (1995). A Systematic Approach to Teaching Interpretation. Silver Spring, MD: Registry of Interpreters for the Deaf. (Translated from French by Jacolyn Harmer)

Sperber, D., \& Wilson, D. (1986). Relevance: Communication and Cognition. Cambridge: Harvard University Press.

Sperber, D., \& Wilson, D. (1995). Relevance: Communication and Cognition (2nd ed.). Oxford: Blackwell.

Wadensjö, C. (1998). Interpreting as Interaction . London and New York: Longman.

$\mathrm{Xu}, \mathrm{W}$. X. (2019). On the Construction of Subjectivity of Football Liaison Interpreters Ph.D. Thesis, Beijing: Beijing Foreign Studies University. 